\title{
Demonstration of multiple HPV types in normal cervix and in cervical squamous cell carcinoma using the polymerase chain reaction on paraffin wax embedded material
}

\author{
N R Griffin, I S Bevan, F A Lewis, M Wells, L S Young
}

\begin{abstract}
The prevalence of human papilloma virus (HPV) types 6, 11, 16 and 18 was investigated using the polymerase chain reaction on formalin fixed, paraffin wax embedded material in 19 cases of cervical squamous cell carcinoma and in 10 normal cervices. HPV DNA was detected in 16 of 19 carcinomas, with multiple types present in 11 of these. HPV 16 or 18, or both, were present in all cases in which HPV was shown. Six of 10 cases of normal cervix contained HPV; five of these contained two or more HPV types, including HPV 16 or 18, or both.

This study shows the feasibility of using the PCR on paraffin wax embedded material and indicates a high rate of carriage of multiple HPV types in both normal and neoplastic cervix.
\end{abstract}

The epidemiology of cervical squamous neoplasia suggests a role for a sexually transmitted infectious agent. ${ }^{1}$ Over recent years interest has focused on human papilloma viruses (HPV) as possible candidates. ${ }^{23}$ These comprise a family of over 50 related viral types, several of which are common sexually transmitted pathogens of the lower genital tract. ${ }^{4}$ Morphological stigmata of infection are often seen in association with cervical intraepithelial neoplasia (CIN). ${ }^{5}$

The development of type specific DNA probes for viral sequences has allowed specific viral subtypes to be identified in clinical material. HPV types 6 and 11 have been associated with benign condylomas and low grades of CIN; types 16 and 18 have been linked to high grade CIN and invasive squamous carcinoma. ${ }^{36}$ It has been suggested that the presence of HPV 16 may confer a high risk of rapid progression of CIN. ${ }^{7}$

These associations have received support from experimental studies showing that HPV 16 encodes a protein mapped in the E6/E7 open reading frames which cooperate with the activated ras oncogene to transform primary rodent cell cultures. ${ }^{8}$ Interestingly, a spliced E6 transcript is only predicted to occur in putative "high risk" HPV types such as 16 and 18 but not in "low risk" types such as 6 and 11 as these lack the appropriate donor/acceptor sequences. ${ }^{9}$

Recent work has thrown doubt on these associations by reporting the presence of HPV
16 in normal cervices. Meanwell et al identified HPV 16 DNA in five of 16 normal cervices and postulated that carriage of HPV was probably a function of increasing age. ${ }^{10}$ Similarly, Murdoch et al have shown that $60 \%$ of biopsy specimens from normal areas of the transformation zone contain HPV 16 DNA. ${ }^{11}$

Comparisons of the reported prevalences of HPV types is difficult as different methods of widely differing sensitivities have been used. The development of the polymerase chain reaction (PCR) ${ }^{12}$ permits detection methods capable of resolving extremely low copy numbers of HPV DNA. The use of these methods, including their application to routine paraffin wax embedded material, ${ }^{13}$ should allow an absolute prevalence of HPV infection to be estimated and may clarify the roles of these agents in cervical oncogenesis.

\section{Methods}

Routinely formalin fixed, paraffin wax embedded blocks of tissue were retrieved from the files of the department of pathology, University of Leeds. Blocks of cervical squamous carcinoma $(n=19)$ were derived from Wertheim's hysterectomy specimens. Haematoxylin and eosin stained sections were reviewed and cases were classified according to the WHO classification. ${ }^{14}$ Blocks of normal cervix $(n=10)$ were obtained from simple hysterectomies carried out for non-cervical disease in patients with no history of abnormal cervical cytology.

HPV sequences were detected by the PCR using oligonucleotide primers complementary to sequences in the E6 region of HPV types 6, 11,16 and 18 (table 1). The primers were designed to amplify segments of differing length in each HPV type.

Four $10 \mu \mathrm{m}$ paraffin wax sections were cut, placed in a single Ependorf tube, and dewaxed in two changes of xylene. After two washes in $95 \%$ ethanol the samples were dried. Water $(250 \mu \mathrm{l})$ was then added and samples were boiled for 30 minutes. A $35 \mu$ l aliquot of the resulting solution was then amplified as described previously. ${ }^{15}$

After amplification samples were incubated for 10 minutes at $70^{\circ} \mathrm{C}$ and $15 \mu$ of the reaction mixture was taken for electrophoresis on $8 \%$ polyacrylamide gels. The reaction products were visualised by ethidium bromide staining. The specificity of the amplified product was confirmed by Southern blotting, ${ }^{16}$ comprising 
Table 1 Sequences of oligonucleotide primers

\begin{tabular}{lllll}
\hline HPV type & & Sequence (5'-3') & Genomic location & $\begin{array}{l}\text { Size of amplified product } \\
\text { (base pairs) }\end{array}$ \\
\hline 6 & A & GCTAATTCGGTGCTACCTGT & $401-420$ & 140 \\
& B & CTGGACAACATGCATGGAAG & $521-540$ & \\
11 & A & CGCAGAGATATATGCATATG & $221-240$ & 90 \\
& B & AGTTCTAAGCAACAGGCACA & $291-301$ & 120 \\
16 & A & TCAAAAGCCACTGTGTCCTG & $421-440$ & 100 \\
18 & B & CGTGTTCTTGATGATCTGCA & $521-540$ & \\
& A & ACCTTAATGAAAAACCACGA & $371-390$ & \\
\hline
\end{tabular}

Figure 1 Amplification of DNA isolated from paraffin wax embedded cervical tissue with $H P V$ 16-specific oligonucleotide primers. Right hand panel: polyacrylamide gel electrophoresis and ethidium bromide staining of products of PCR. Left hand panel: Southern blot probed with HPV 16 probe confirming specificity for HPV 16 DNA. Key: CaSki, CaSki cell DNA (HPV 16 positive

control); FL 664, fetal liver DNA (negative control); 76, 79, 78, 83, $77,82,84, D N A$ extracts from paraffin wax embedded cervical carcinomas; $M, D N A$ size markers.
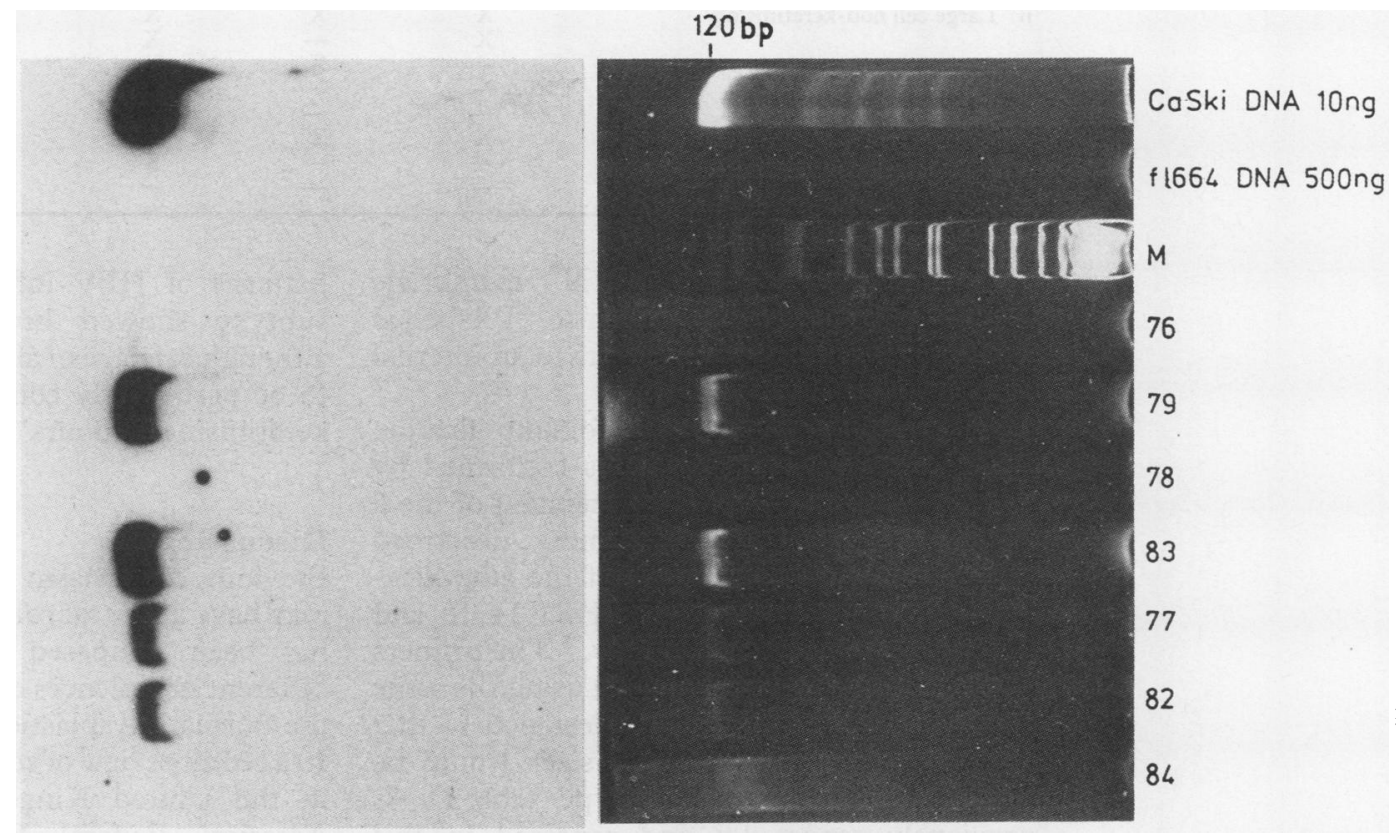

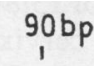

HPV II DNA IOng

M

fl664 DNA 500ng

76

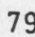

78

83

77

82

84

Figure 2 Amplification of DNA isolated from paraffin wax embedded cervical tissue. Right hand panel: Southern blot of products amplified with $H P V 6$ specific primers hybridised to HPV 6 probe. Left hand panel: Identical procedure using HPV 11 specific primers and probe. Key: HPV DNA 6, 11, plasmid DNA positive controls; FL 664, fetal liver negative control DNA; 76, 79, 78, 83, 77, 82, 84, DNA extracts from paraffin wax embedded cervical carcinomas. 
Table 2 Patterns of HPV carriage shown by PCR

\begin{tabular}{|c|c|c|c|c|c|}
\hline \multirow[b]{2}{*}{ Histological diagnosis } & \multicolumn{5}{|c|}{ HPV type } \\
\hline & 6 & 11 & 16 & 18 & $n=$ \\
\hline Normal cervix & $\begin{array}{l}\frac{\mathrm{x}}{-} \\
\frac{\bar{x}}{\mathrm{x}}\end{array}$ & $\begin{array}{l}\frac{\mathrm{x}}{\mathrm{x}} \\
\mathbf{x} \\
\frac{\mathbf{Z}}{-}\end{array}$ & $\begin{array}{l}\frac{\bar{x}}{\mathrm{x}} \\
\frac{\mathrm{x}}{-} \\
\overline{-}\end{array}$ & $\begin{array}{l}\mathbf{x} \\
\mathbf{x} \\
\mathbf{x} \\
= \\
= \\
-\end{array}$ & $\begin{array}{l}1 \\
1 \\
1 \\
1 \\
1 \\
1 \\
4\end{array}$ \\
\hline $\begin{array}{l}\text { Squamous cell carcinoma } \\
\text { i) Large cell keratinising }\end{array}$ & $\begin{array}{l}\frac{\mathrm{X}}{\mathrm{X}} \\
\frac{\mathrm{x}}{\mathrm{X}} \\
\end{array}$ & $\begin{array}{l}\mathbf{x} \\
\mathbf{x} \\
- \\
-\end{array}$ & $\begin{array}{l}\mathbf{X} \\
\mathbf{X} \\
\mathbf{X} \\
\mathbf{X}\end{array}$ & $\begin{array}{l}\frac{\mathrm{x}}{\mathrm{x}} \\
\frac{\mathrm{x}}{-}\end{array}$ & $\begin{array}{l}1 \\
1 \\
1 \\
1 \\
1 \\
2\end{array}$ \\
\hline ii) Large cell non-keratinising & $\begin{array}{l}\mathbf{X} \\
\mathbf{x} \\
-\end{array}$ & $\frac{\frac{x}{x}}{-}$ & $\begin{array}{l}\mathbf{X} \\
\mathbf{X} \\
\mathbf{x} \\
-\end{array}$ & $\frac{\bar{x}}{\bar{x}}$ & $\begin{array}{l}2 \\
1 \\
1 \\
2 \\
1\end{array}$ \\
\hline iii) Small cell non-keratinising & $\frac{\mathbf{x}}{-}$ & $\frac{x}{-}$ & $\begin{array}{l}\mathbf{x} \\
\mathbf{x} \\
-\end{array}$ & $\begin{array}{l}\mathbf{X} \\
\mathbf{X} \\
\mathbf{X}\end{array}$ & $\begin{array}{l}3 \\
1 \\
1\end{array}$ \\
\hline
\end{tabular}

electroblotting on to Hybond $-\mathbf{N}+$ membrane (Amersham) and hybridisation to ${ }^{32} \mathrm{P}$ labelled oligonucleotide probes (40-mer) to an internal area of the amplified sequence.

The suitability of the DNA for amplification in each cervical specimen was confirmed by successful amplification of a fragment of the $\beta$ globin gene using the primers described previously. ${ }^{12}$ The specificity of the amplification technique and primers for HPV 11, 16, and 18 have been shown previously. ${ }^{15}$ The primers used for HPV 6 were validated using the same methods. The primers were designed so that target sequences of different sizes would be amplified according to HPV type (table 1). As previously reported, ${ }^{15}$ and repeated in this study, the sizes of the amplified products were as predicted from the primer design. The specificity of the reaction was further confirmed by the absence of bands when HPV type specific primers were used in reactions containing HPV DNA of a different type. In each assay appropriate negative (lymphoblastoid cell lines and fetal liver DNA) and positive (CaSki and HeLa cell DNA for HPV 16 and 18, respectively; plasmid DNA for HPV 6 and 11) controls were included (lanes 1 and 2, fig 1; lanes 1 and 3, fig 2, right hand panel and lanes 2 and 3, fig 2, left hand panel) and produced the predicted results.

\section{Results}

The results are shown in table 2. Amplification of the $\beta$ globin gene was successfully carried out in all cases studied. Examples of ethidium bromide stained gels and Southern blots are shown in figs 1 and 2.

HPV DNA was detected in six of $10(60 \%)$ cases of normal cervix. Of these, five contained two or three HPV types including types 16 or 18 , or both.

HPV DNA was detected in 16 of $19(84 \%)$ of cases of squamous cell carcinoma. Of these, four HPV types were found in six cases, three types in one case, two types in five cases and one type in five cases. HPV types 16 or 18 , or both, were present in all cases containing demonstrable HPV DNA. Comparisons of patterns of HPV infection with histological subtype showed broadly similar patterns, although carriage of all four HPV types seemed to be particularly common in small cell nonkeratinising tumours (three of five cases).

\section{Discussion}

Previous enthusiasm for the view that HPV may have a central role in cervical oncogenesis has been tempered by reports of widely different prevalences of different HPV types in the normal, dysplastic, and neoplastic cervix. In a recent review of studies of HPV prevalence in the United Kingdom, United States of America, Federal Republic of Germany, Central and South America and Japan, ${ }^{17}$ rates for HPV 16 or 18 , or both, in invasive squamous cell carcinoma ranged from 15.4 $92 \%$. Similarly, ranges of $13.8-83.3 \%$ for CIN and $0-45 \%$ for healthy cervix were recorded. While this may reflect true global variation in prevalence, it is highly likely that variation in study design and sensitivity of detection techniques are important.

The use of the PCR has improved sensitivity by orders of magnitude such that theoretically a single HPV copy can be detected in a background of $10^{5}$ cells. $^{15}$ This technique should thus allow the "true" absolute levels of HPV infection to be estimated. The technique has recently been validated and applied to HPV detection in cervical cytology specimens, ${ }^{15} 18$ leading to the detection of HPV16 in $70-84 \%$ of "normal" cases. The applicability of the technique to routine formalin fixed, paraffin wax embedded tissue extends the possibilities for study to archive material.

The present study confirms a high rate of carriage of HPV in normal cervices with six of 10 cases containing HPV, including five cases containing the putatively "high risk" types 16 and 18. The prevalence of HPV 16 (three of 10 cases) is lower than the $70-84 \%$ obtained in studies of cytology specimens. ${ }^{15} 18$ This may represent sampling differences, although it is suggested that full thickness biopsy specimens, such as those used in the present study, are likely to be a more sensitive method of detect- 
ing HPV than cytological preparations. ${ }^{10}$ More likely, perhaps, is the possibility that the PCR is decreased in sensitivity when used on paraffin wax embedded material. Reconstruction experiments using paraffin wax embedded mixtures of cultured cells containing known HPV copy loads indicate that the technique can detect between 100-400 HPV copies per reaction mixture, ${ }^{19}$ a probable reduction in sensitivity of $10-40$ times compared with cytological preparations. ${ }^{15}$ The possibility of true population differences cannot, of course, be excluded.

The finding of HPV DNA in $84 \%$ of squamous cell carcinomas is broadly in line with previous studies from the United States of America and China using the PCR on paraffin wax embedded material. ${ }^{2021}$ The possibility of multiple HPV carriage has not been widely addressed in previous studies, although infection by multiple viruses such as HPV, herpes simplex type 2, cytomegalovirus, and EpsteinBarr virus have been documented in cervical neoplasia by both serological and molecular biological methods. The role of such multiple infections in neoplasia remains to be established. $^{22-24}$

Our results indicate that multiple HPV carriage is a relatively common phenomenon. Two or more HPV types were shown in 11 of 16 cases of squamous cell carcinoma that contained HPV. Similarly, five of six normal cases containing HPV had two or more types demonstrable. Associations between particular HPV types and histological subtypes of cervical carcinoma, suggested in a recent study, ${ }^{25}$ were not demonstrable in our results, although the particularly high rate of carriage of all four HPV types investigated in small cell nonkeratinising squamous cell carcinomas is noteworthy. The number of cases investigated was, however, relatively small.

This study confirms the previous findings of PCR investigations on cervical cytology specimens ${ }^{1518}$ in showing that the relations between carriage of "high" and "low risk" HPV types and cervical neoplasia is not as clear cut as previously thought. This might be a consequence of the higher sensitivity of PCR based techniques and may indicate that high copy numbers of "high risk" HPV types are necessary for oncogenesis. This hypothesis is not supported by a recent study in which high copy numbers were found in cells derived from normal cervices as well as from cases of $\mathrm{CIN} .^{26}$ The recent demonstration that HPV 16 may be divided into two subtypes, only one of which is associated with neoplasia, ${ }^{27}$ is interesting and may explain the apparently common occurrence of HPV 16 in healthy cervices. Confirmation of this important result, however, has not yet been forthcoming. The finding of a high rate of carriage of putatively oncogenic viruses in a normal population does not necessarily militate against a role for HPV in cervical oncogenesis and suggests parallels with accepted oncogenic viruses such as Epstein-Barr virus. This virus is extremely widely distributed in man, irrespective of the incidence of associated malignancies, and the presence of cofactors is strongly implicated in the oncogenic process. A similar situation exists with many animal tumour viruses. ${ }^{4}$

Epidemiological evidence strongly implicates smoking as a cofactor in cervical carcinogenesis, ${ }^{28}$ and possible effects of cigarette smoke derived materials on local immunocompetent cells in the cervix have been shown..$^{29}$ It remains to be shown whether smoke derived products are capable of directly damaging cervical DNA, although the methodology to address this question is well established. ${ }^{30}$

The PCR has shown that factors other than the simple presence of a putatively oncogenic virus probably affect cervical oncogenesis. Several different approaches will clearly be necessary to elucidate fully the role of HPV in cervical disease.

NRG is supported by a grant to $M W$ from the Yorkshire Cancer Research Campaign. LSY and ISB are supported by the Cancer Research Campaign, London.

1 Zunzinegui MV, King MC, Coria CF, Charlet J. Male influence on cervical cancer risk. Am J Epidemiol 1986;123:302-7.

2 zur Hausen H. Genital papillomavirus infections. Prog Med Virol 1985;32:15-21.

3 Howley PM. On human papillomaviruses. $N$ Engl J Med 1986;315:1089-90.

4 Meanwell CA. The epidemiology of human papillomavirus infection in relation to cervical cancer. Cancer Surv 1988;7:481-97.

5 Fletcher S. Histopathology of papillomavirus infection of the cervix uteri: the history, taxonomy, nomenclature and reporting of koilocytic dysplasias. J Clin Pathol 1983;36:616-24

6 Pfister H. Human papillomaviruses and genital cancer. $A d v$ Cancer Res 1987;48:113-47.

7 Campion MJ, McCance DJ, Cuzick J, Singer A. Progressive potential of mild cervical atypia: prospective cytological, colposcopic and virological study. Lancet 1986; i:237-40.

8 Matlashewski G, Schneider J, Banks L, Jones N, Murray A, Crawford L. Human papillomavirus type 16 DNA cooperates with activated ras in transforming primary cells. EMBO J 1987;6:1741-6.

9 McCance DJ. News on papillomaviruses. Nature 1988;335:765-6.

10 Meanwell CA, Blackledge G, Cox MF, Maitland NJ. HPV16 DNA in normal and malignant cervical epithelium: implications for the aetiology and behaviour of cervical neoplasia. Lancet 1987;i:703-7.

11 Murdoch JB, Cassidy LJ, Fletcher K, Cardiner JW, Macnab JCM. Histological and cytological evidence of viral infection and human papillomavirus type 16 DNA sequences in cervical intraepithelial neoplasia and normal tissue in the west of Scotland: evaluation of treatment policy. Br Med J 1988;296:381-5.

12 Saiki RK, Scharf S, Faloona F, et al. Enzymatic amplification of $\beta$-globin genomic sequences and restriction site analysis for diagnosis of sickle cell anaemia. Science analysis for diag

13 Shibata DK, Arnheim N, Martin WJ. Detection of human papilloma virus in paraffin embedded tissue using the polymerase chain reaction. $J \operatorname{Exp} M e d$ 1988;167:225-30.

14 Poulsen HE, Taylor CW, Sobin LH. Histological typing of female genital tract tumours. International histological classification of tumours. No 13. Geneva: World Health Organisation, 1975:57-8.

15 Young LS, Bevan IS, Johnson MA, et al. The polymerase chain reaction: a new epidemiological tool for the investigation of cervical HPV infection. Br Med J 1989;298:14-8.

16 Cox MF, Meanwell CA, Maitland NJ, Scully C, Blackledge G, Jordan JA. Demonstration of HPV16 homologous DNA in the normal human ectocervix. Lancet 1986;ii: 157-8.

17 Munoz N, Bosch X, Kaldor JW. Does human papillomavirus cause cervical cancer? The state of the epidemiological evidence. Br J Cancer 1988;57:1-5.

18 Tidy JA, Parry GCN, Ward P, et al. High rate of human papillomavirus type 16 infection in cytologically normal cervices. Lancet 1989;i:434.

19 Shibata D, Fu YS, Gupta JW, Shah KV, Arnheim N, Martin WJ. Detection of human papillomavirus in normal and dysplastic tissue by the polymerase chain reaction. Lab Invest 1988;59:555-9.

20 Kiyabu MT, Shibata D, Arnheim N, Martin WJ, Fitzgibbons PL. Detection of human papillomavirus in formalin-fixed invasive squamous carcinomas using the polymerase chain reaction. Am J Surg Pathol 1989;13: $221-4$.

21 Xiao X, Cao M, Miller TR, Cao Z, Benedict Yen TS. 
Papillomavirus DNA in cervical carcinoma specimen from central China. Lancet 1988;ii:902.

22 Schmauz R, Okong P, deVilliers EM, et al. Multiple infections in cervical cancer from a high incidence area in tropical Africa. Int J Cancer 1989;43:805-9.

23 Diluca D, Costa S, Monini P, et al. Search for human papillomavirus, herpes simplex virus and c-myc oncogene in human genital tumours. Int $J$ Cancer 1989;43:570-7. 24 Bevan IS, Blomfield PI, Johnson MA, Woodman CBJ,
Young LS. Oncogenic viruses and cervical cancer. Lancet 1989;i:907-8.

25 Wilczyski SP, Bergen S, Walker J, Liao S-Y, Pearlman LF. Human papillomaviruses and cervical cancer: analysis of Human papillomaviruses and cervical cancer: analysis of

types. Hum Pathol 1988;19:697-704.
26 Wickenden C, Malcolm ADB, Byrne M, Smith C, Anderson
MC, Colman DV. Prevalence of HPV DNA and viral copy numbers in cervical scrapes from women with normal and Tidnormal cervices. J Pathol 1987;153:127-35.

7 Tidy JA, Vousden KN, Farrell PJ. Relation between infection with a subtype of HPV16 and cervical neoplasia. Lancet $1989 ; \mathrm{i}: 1225-7$.

28 LaVecchia C, Franchescha S, Decorli A, et al. Cigarette smoking and risk of cervical neoplasia. Am J Epidemio 1986;123:22-7.

29 Barton SE, Jenkins D, Cuzick J, Maddox PA, Edwards R Singer A. Effect of cigarette smoking on cervical epithelial immunity: a mechanism for neoplastic change? Lancet 1988;ii:652-4.

30 Reddy MV, Randerath K. Nuclease Pl-mediated enhancement of sensitivity of ${ }^{32}$ P-postlabeling test for structurally ment of sensitivity of ${ }^{32-}$-P-postlabeling test for structurally
diverse DNA adducts. Carcinogenesis 1986;7:1543-51. 